\title{
Algorithms and the near future of design Euan Mills
}

\section{Introduction by Silvio Carta}

In this article Euan Mills, who co-leads the Plantech programme at Connected Places Catapult, reflects on the changes of the design, planning and construction industries. The Connected Places Catapult is a centre devoted to the development and advancement of innovation in cities supported by the UK government. In this multidisciplinary team, planners, urban designers and many other experts collaborate with the public and private sectors, informing the design and construction industries as well as influencing policy-makers. In recent years, Euan and colleagues have been particularly active in engaging with academics, designers and the public in devising new ways in which the planning system in the UK can be improved and updated taking full advantage of new digital technologies and computational approaches to design increasingly available today. Under the title of Plantech (Connected Places Catapult 2019), Euan and colleagues are promoting a new planning agenda whereby in a near future urban data, people's input and the regulatory system can converge into a seamless framework. Not only this would significantly simplify the planning system and the relationship that residents have with planning authorities and designers but, more importantly, it will synchronise some of the workflows that characterise urban planning and permissions (often with scanned version of old documents, historical paper archives etc.) with the digital assemblage of big data that is the fabric of our cities today.

The "Architecture is in a sort of crisis" claims David Chiperfield (Dalley 2018), but new technology presents an opportunity for architects to re-invent themselves as central to the production of the built environment. To do so, we need to embrace the fundamentals of internet-era technologies and rethink how architectural knowledge is distributed and accessed.

The design of our built environment has never been as important as it is today. The unprecedented rate of urban population growth is breath-taking, but even more dramatic is the rate of growth of urban footprints, twice that of urban populations. Of all this new building only about $1-2 \%$ are designed by architects. In the UK, the figure is slightly higher at just over $15 \%$, but if you focus on the design of housing, according to the RIBA, that figure falls to $6 \%$. (Morris 2018). Whichever way you see it, the influence of architecture in the built environment has been diminished. Architectural quality tends to be the reserve of exceptional buildings, which generally have limited impact, despite being celebrated in the architectural press and inspiring architecture students across the globe. In the words of Carlo Ratti in his book Open Source Architecture (Ratti and

Stable URL: https://arcc-journal.org/index.php/arccjournal/article/view/1062 10.17831/enq:arcc.v16i1.1062

Corresponding Author: Euan.Mills@futurecities.catapult.org.uk

Published by the Architectural Research Centers Consortium under the terms of the Attribution-NonCommercial-ShareAlike 4.0 International license 
Claudel 2015), "the engine of architecture has become geared toward the privileged few."

When architects do get involved in designing buildings, commercial pressures from clients is an overwhelming factor in their work. The economic impetus of maximising the number of homes on a site, for example, will define layout, typology and scale of buildings. We've moved into an era where form follows finances. The role of the architect is relegated to styling elevations or providing a design rationale for a development shaped mostly by economic forces. The best architects manage to negotiate with clients and find a compromise between the need to maximise value and achieve quality. More often than not though, it'll be the planning regulations that impose quality standards such as levels of daylight and sunlight or maximum densities. "Architects used to be connected to good intentions, notionally at least. With the market economy, we've slowly found ourselves supporting, at best, individual ambitions and, at worst, pure profit motives." says Rem Koolhaas (Budds 2016).

A quick glance inside a medium sized architecture office and you'll also see the work of architects has also diminished in value. Research by OMA shows an average of $50 \%$ of architects time is spent on the design of buildings, but even this figure might be optimistic. Most architects spend the majority of their time solving common recurring design problems, producing and reproducing drawings, then justifying decisions to clients, planners and local communities. This process is laborious, time consuming, and prone to errors, leading to long work hours and low productivity. A study from the American Institute of Architects found that 57 per cent of architects already copy-and-paste details from previous projects to save time (B2B International 2016). After all, there are only so many ways you can lay out a bathroom, detail a window reveal or layout apartments around a core.

The scarcity of the architect's time is compounded by the hours spent on speculative and unrealised work often unpaid. Projects which are never realised, because they were merely an output of land speculation, or because of 'design and build' contracts value engineer their work beyond recognition. The way in which the industry unashamedly celebrates this in 'unbuilt' categories of architectural competitions is symptomatic of this. Every day spent on this type of work is an hour less spent on trying to solve thousands of the urban challenges cities are plagued with today. Unsurprisingly, architecture is now a profession in the 'Shortage Occupation List' of the home office in the UK.

The architecture profession could be said to be over 4000 years old. While new technologies have emerged creating new ways to solve old age problems, basic human needs have remained unchanged in that time. Yet, instead of a growing body of architectural knowledge from which each new generation of architects can learn and add to, architects today have a tendency to obfuscate and mystify their work. Look through any Design and Access Statement recently submitted to a local planning authority. Instead of references to empirical research justifying design decisions, you'll find them packed with metaphors and analogies that justify the design. In the words of Jan Gehl, we "know more about good habitats for mountain gorillas, Siberian tigers, or panda bears than we do know about a good urban habitat for Homo sapiens" (Green 2019). Given the scale and complexity of designing the built environment, from the orientation of streets to the size of bedrooms, and the impact these decisions have on a city for decades to come; the lack of empirical research, post-occupancy assessments and evidence-based design is astounding.

Whilst the architecture profession struggles with its purpose, we are witnessing the biggest change to society since the industrial revolution. The relentless march of Moore's Law has brought us to an age of ubiquitous computing. Sensors, social media and computer vision technologies are allowing us to collect unprecedented quantities of data about ourselves and the built environment. Cheap and powerful computers can rapidly analyse and learn from this data and create ever more powerful and precise algorithms.

This ' $4^{\text {th }}$ industrial revolution' has created a shift in the way we organise human knowledge. Once the preserve of scholars, knowledge became accessible to many more through the invention of libraries and the printing press. Today, the spread of knowledge made possible through digital technology makes this pale in comparison. We can now access the totality of human knowledge in a heartbeat. Larry Sanger, the founder of Wikipedia, describes how "professionals are no longer needed for the bare purpose of the mass distribution of information and the shaping of 
opinion." (Sanger 2019). Wikipedia has over 40 million articles in more than $\mathbf{3 0 0}$ different languages, with an accuracy comparable to that of Encyclopedia Britannica, all written and distributed for free. Google Books has over 25 million books scanned, indexed and searchable. Whilst still only a fraction of the 130 million titles in existence, they continue to scan books faster than they are published. This new paradigm in how we organise and access knowledge will also create a shift in the nature of professions, the gatekeepers of domain expertise.

With all of human knowledge digitised and cloudbased, we are rapidly moving into a position where we can create algorithms that can learn and deploy this knowledge in practical situations in our everyday lives. Despite the impressive repository of medical knowledge that is Web MD, many of the 80 million visits per month are from medical professionals themselves. The algorithms behind IBM's Watson and Babylon Health are the real game-changer. These services refer to similar repositories of medical knowledge but have created systems that allow patients to self-diagnose without any involvement from doctors. This quick and easy level of interaction combined with machine learning means these systems can learn and identify symptoms with a growing level of certainty and exponentially grow the knowledge base itself. Not only will this produce increasingly better diagnosis, but it will allow the 45,000 GP's working in the UK to focus on the more complex and sensitive parts of their work.

The same is happening to legal professions. Richard Suskind has been working with the Courts and Judiciary Tribunals in the UK to adopt similar systems for the1.4 million Civil Claims the UK courts deal with annually ("Lord Chief Justice sets up" 2019). Ebay's Online Dispute Resolution systems already solves approximately 60 million disputes a year, removing a huge number of what would otherwise become Civil Claims (Louis et al 2014). The efficiencies this creates is only secondary to the improved quality. As Hannah Fry illustrates in her book Hello World, algorithms, despite their own shortcomings, can be significantly more consistent and less biased than human judges in sentencing.

"We are on the brink of a period of fundamental and irreversible change in the way that the expertise of these specialists is made available in society" (Jacskon 2016) Richard Suskind points out in his Book, The Future of Professions. With both the medical and legal professions being transformed before us, the architecture industry needs to move with the times.

As set out in the beginning of this article, despite the growing urgency and need for architectural knowledge and expertise, the 54,000 architects working in the UK today are not having the impact we need. Architectural knowledge, such as where to best locate a radiator, the ideal width of bedrooms or the orientation of streets to maximise sunlight, needs to be opened up and distributed in a more equitable way if we are to ensure that cities will remain places we want to live in in the future.

There are many interesting precedents for how we can do this. As early as the 1970's Christopher Alexander talked about the democratisation of architectural expertise through the creation of "architectural patterns" as a way of distributing knowledge to common recurring architectural problems, redressing the balance of knowledge between professionals and the wider public. His book Pattern Language (1977) was an attempt to bring all these 'patterns' into one place and make them accessible to all. The idea of patterns was influenced by early computer programmers, who would write standard lines of code that could be easily used to solve common occurring problems. Today software patterns are stored in huge 'Git repositories', with advanced version control mechanisms, which allow software developers across the globe to contribute towards improving individual patterns and building the vast libraries of open source code we have today.

In 2016, the architecture practice Elemental decided to openly distribute their designs (including original DWG files of plans, sections, elevations and details) for a social housing project in the hope that others would copy them and improve the quality of social housing being delivered. In the same vein as Christopher Alexander, this was an attempt to make architectural knowledge accessible to all. In this case, Elemental were distributing the final output, rather than the knowledge and expertise that helped develop them, making it hard for others to adapt designs to different locations. Nonetheless, the principle of architects distributing knowledge in this way established an important parallel with the development of open source software and its rapidly escalating impact. 
Organisations such as the non-profit Open Systems Lab are putting many of these ideas into practice. Their Build $X$ platform translates spatial configuration directly into manufacturing and cost requirements, short circuiting the supply chain of consultants that sell their expertise on a project-byproject basis.

Others such as Testfit and Hypar are trying to capitalise on the commercial opportunities in these technologies. The former is automating aspects of the design process and the latter want to help architects monetise expertise through scalable cloud services Anthony Hauck, founder of Hypar, claims "there is an enormous amount of latent demand. If this expertise was as widely available as WebMD, Rocket Lawyer, and TurboTax, then maybe we'd get a better built environment" (Davis 2019).

The architecture industry has always been relatively fast at embracing new technologies. The move from drawing boards to CAD and now BIM and virtual reality are well underway. The next stage will be the creation and distribution of algorithms that implement architect's low value, high volume work. This will, for the first time create a more fundamental shift in the business model of architectural practices. Early manifestations are already taking shape, with algorithms that allow us to lay out apartments or work out housing capacity for vacant sites. As these become common practice, we'll start seeing architectural practices provide access to pay-per-use algorithms directly to clients, who can apply them to their sites and tailor design options on a self-service basis. We will also see a growth in open source architectural algorithms, distributed for free and modified and revised over and over again, like open source computer code, becoming better at every iteration.

This next stage of technological innovation in architecture has the potential to, not only, make the practice of architecture more efficient and commercially viable; but help us build faster and better cities across the globe.

\section{References}

"Lord Chief Justice sets up advisory group on Artificial Intelligence" Courts and Tribunals Judiciary. Mar 4, 2019.

https://www.judiciary.uk/announcements/lordchief-justice-sets-up-advisory-group-on-artificialintelligence/ last accessed 31 Oct 2019

Alexander, Christopher. A pattern language: towns, buildings, construction. Oxford university press, 1977.

B2B International. The Architect Specification Journey: Understanding the Role of Building Product Manufacturers Today \& Tomorrow," American Institute of Architects. 2016.

Budds, Diana. "Rem Koolhaas: Architecture Has A Serious Problem Today". Fast Company. 21 May 2016 https://www.fastcompany.com/3060135/remkoolhaas-architecture-has-a-serious-problem-today last accessed 31 Oct 2019

Dalley, Jan. David Chipperfield: 'Architecture is in a sort of crisis'. Financial Times. 4 May 2018. https://www.ft.com/content/617a3a3c-4ed9-11e8-

a7a9-37318e776bab last accessed 31 Oct 2019

Davis, Daniel. Can Algorithms Design Buildings? Architect. 24 June 2019.

https://www.architectmagazine.com/technology/ca n-algorithms-design-buildings_o last accessed 31 Oct 2019

Future Cities Catapult. https://futurecities.catapult.org.uk/project/futureof-planning/ Last accessed 19 November 2019

Green, Jared. INTERVIEW WITH JAN GEHL. The American Society of Landscape Architects. 2019. https://www.asla.org/ContentDetail.aspx?id=31346 last accessed 31 Oct 2019

Jackson, Robin. Review: The Future of the Professions by Richard Susskind and David Susskind. Centre for Welfare Reform. 2016.

https://www.centreforwelfarereform.org/library/the -future-of-the-professions.html last accessed 31 Oct 2019

Louis F. Del Duca, Colin Rule \& Kathryn Rimpfel. eBay's De Facto Low Value High Volume Resolution Process: Lessons and Best Practices for ODR Systems Designers, 6 Y.B. Arb. \& Mediation, 204. 2014. 
Ratti, Carlo, and Matthew Claudel. Open source architecture. London: Thames \& Hudson, 2015.

Morris, Neal. Finding ways to design for the public good. RIBA. 21 June 2018.

https://www.architecture.com/knowledge-andresources/knowledge-landing-page/finding-ways-todesign-for-the-public-good._Last accessed 18 Nov 2019

Sanger, Larry. WHO SAYS WE KNOW: ON THE NEW POLITICS OF KNOWLEDGE". Edge. 2019 https://www.edge.org/conversation/larry_sanger-

who-says-we-know-on-the-new-politics-of-

knowledge last accessed 31 Oct 2019 